\title{
ECONOMIC COSTS OF HEALTH INEQUALITIES IN THE EUROPEAN UNION
}

Johan P. Mackenbach, Willem J. Meerding, Anton E. Kunst

Department of Public Health

Erasmus MC

University Medical Center Rotterdam

P.O. Box 2040

3000 CA Rotterdam

The Netherlands

Address for correspondence: Prof. Dr J.P. Mackenbach (email:

j.mackenbach@erasmusmc.nl)

Competing interests: none declared. 


\section{What this paper adds}

What is already known on this subject?

- In all countries with available data, significant inequalities in health exist between socioeconomic groups.

- Tackling these health inequalities requires action in many policy areas, including policy areas outside the health care system.

- A fruitful dialogue with policy areas outside the health care system is likely to be facilitated if the economic costs of health inequalities are known.

- Existing analyses of the costs of ill-health focus on average health, and we have therefore explored the economic costs of socioeconomic inequalities in health.

What does this study add?

- Inequalities-related losses to health amount to more than 700,000 deaths per year, and 33 million prevalent cases of ill-health, in the European Union as a whole.

- Inequalities-related losses to health reduce labour productivity and take $1.4 \%$ off GDP each year.

- The monetary value of health inequalities-related welfare losses is estimated to be $€ 980$ billion per year, or $9.4 \%$ of GDP.

- Inequalities-related losses to health account for $20 \%$ of the total costs of health care, and $15 \%$ of the total costs of social security benefits.

- If our results are confirmed in further studies, the economic implications of health inequalities warrant significant investments in policies and interventions to reduce them. 


\begin{abstract}
Background

In order to support the case for intersectoral policies to tackle health inequalities, we have explored the economic costs of socioeconomic inequalities in health in the European Union, $\underline{\text { Methods }}$

Using recent data on inequalities in self-assessed health and mortality covering most of the European Union, we calculated the health losses due to socioeconomic inequalities in health by applying a counterfactual scenario in which the health of those with lower secondary education or lower (roughly $50 \%$ of the population) would be improved to the average level of health of those with at least higher secondary education. We then calculated various economic effects of those health losses: health care costs, costs of social security schemes, losses to Gross Domestic Product through reduced labour productivity, and the monetary value of total losses in welfare.

\section{$\underline{\text { Results }}$}

Inequalities-related losses to health amount to more than 700,000 deaths per year, and 33 million prevalent cases of ill-health, in the European Union as a whole. These losses account for $20 \%$ of the total costs of health care, and $15 \%$ of the total costs of social security benefits. Inequalities-related losses to health reduce labour productivity and take $1.4 \%$ off GDP each year. The monetary value of health inequalities-related welfare losses is estimated to be $€ 980$ billion per year, or $9.4 \%$ of GDP.

\section{Conclusion}

Our results suggest that the economic costs of socioeconomic inequalities in health in Europe are substantial. As this is a first attempt at quantifying the economic implications of health inequalities, the estimates are surrounded by considerable uncertainty, and further research is needed to reduce this uncertainty. If our results are confirmed in further studies, the economic implications of health inequalities warrant significant investments in policies and interventions to reduce them.
\end{abstract}




\section{Introduction}

In recent years there has been growing attention to the potential economic benefits of improvements in population health. This is far from new: historically, one of the origins of the public health movement lies in the awareness that the prosperity of nations is partly dependent on the health of their populations [1]. But this awareness has received a new stimulus from the publication in 2001 of the report of the WHO Commission on Macroeconomics and Health, which demonstrated that health improvement can be seen as a key strategy for income growth and poverty reduction in low- and middle-income countries [2]. This report was followed in 2005 by an overview of evidence concerning the impact of health on the economy in high-income countries, particularly the European Union [3]. Both this and a later follow-up report by the same authors on the costs of ill health in the European region [4] concluded that there are good economic arguments for investing in health - if Europe is to become more competitive globally, greater investments in human capital are necessary. It took the view that health should not only be seen as a 'capital good', which improves productivity and economic output, but also as a 'consumption good', which should be valued in itself as one important component of total 'welfare'.

Most analyses of the relationship between health and the economy focus on average health, but health is very unevenly distributed across society. In all countries with available data, significant inequalities in health exist between socioeconomic groups, in the sense that people with lower levels of education, occupation and/or income tend to have systematically higher morbidity and mortality rates [5]. These health inequalities are one of the main challenges for public health, and there is a great potential for improving average population health by eliminating or reducing the health disadvantage of lower socioeconomic groups. This requires an active engagement of many policy sectors, not only of the public health and health care systems, but also of many other policy areas, including education, social security, working life, city planning, et cetera [6].

A fruitful dialogue between the public health and health care sector on the one hand, and other policy areas on the other hand, is likely to be facilitated if the economic costs of 
health inequalities are known, and if the economic benefits of reducing health inequalities can be made clear. What would be the economic impact of improving the health of groups with a lower socioeconomic status to that of more advantaged sections of the population? Answering this question is currently impossible, because it requires insight in the costs and effects of policies which will reduce health inequalities, and this is not yet available [7]. A first step in this direction, however, would be to quantify the current economic losses which health inequalities generate. In the study reported in this paper we have tried to estimate the total inequalities-related losses to population health in the European Union, and from there on made estimates of the impact of these health losses on labour productivity and Gross Domestic Product and on total welfare, as well as on health care costs and costs of social security benefits. 


\section{Data and methods}

\section{The levelling up approach}

Socioeconomic inequalities in health usually present themselves as a gradient, characterized by a systematic increase of the rates of morbidity and mortality as one moves down the social ladder [8]. Part of this association is likely to be causal, in the sense that lower positions in the social hierarchy expose people to a variety of health risks (unfavourable living and working conditions, psychosocial factors, health behaviours, ...) [9]. This suggests that socioeconomic inequalities in health can be reduced by improving the life situations of people with lower levels of education, occupation or income, e.g. by giving people with lower socioeconomic positions a higher education or income, or by changing their lifestyles and living conditions. Most analyses of opportunities for reducing health inequalities conclude that policies and interventions should aim for an 'upward levelling' of health inequalities, by which the higher rates of morbidity and mortality of the lower socioeconomic groups are reduced to the level of more advantaged groups in society [10].

We have used this 'upward levelling' perspective to determine how much ill-health in the population is attributable to the fact that not everybody has a high level of education, a high occupational class, or a high income level. Our approach is closely related to the measure of 'Population-Attributable Risk' (PAR) [11], which is often used in epidemiology to quantify the burden of ill health or premature mortality associated with specific risk factors such as smoking and overweight. In a similar way, the PAR approach can be used to estimate how much ill-health in the population is attributable to the fact that not everybody has a high level of education, a higher occupational class, or a high income level [12]. In order to calculate the impact of health inequalities on over-all population health we will compare the current situation in European countries to the hypothetical situation that everyone would have the health status corresponding to a high socioeconomic position. We will not attempt to specify how such a situation could realistically be achieved, but just use this counterfactual situation to estimate the losses to 
population health which are currently generated by health inequalities. We will use a simple dichotomy between low and high socioeconomic status, in which 'high' socioeconomic positions are conservatively defined as roughly the upper $50 \%$ of the population.

Socioeconomic status will be indicated by educational level. Our preference for this indicator is in part based on pragmatic reasons, because educational level is the only indicator of socioeconomic position available in different types of data sets for most European countries. A theoretical advantage is that educational level is established before full adulthood, and therefore is less sensitive to reverse causality. Recent studies have shown that educational inequalities in mortality and morbidity are indeed likely to reflect a causal effect of education on health outcomes [13].

Our calculations were carried out in the three steps described below. All data apply to 2004, and are for the European Union as a whole (EU-25, before the recent enlargement to EU-27). Further details on sources of data, calculation procedures and methodological evaluations can be found in a full report [14].

\section{Estimation of the inequalities-related burden of ill-health and premature mortality}

We first made estimates of the relative risk of mortality and self-reported ill-health of lower as compared to higher educational groups. These relative risk estimates were combined with information on absolute mortality and prevalence rates in the European Union in 2004, as available from the Eurostat website, to obtain mortality rates and prevalence rates according to educational level.

For mortality, we estimated the age-standardized mortality rate to be 36 percent higher in lower educated as compared to higher educated. This estimate was primarily derived from a study covering 10 western European populations representative of the EU-15 [15]. In this study, rate ratios were calculated per 10-year age group for men and women, for the age group 30-39 to 90+ years. We calculated the weighted average of the age-specific 
rate ratios, which was 1.31 for men and women together (who were given equal weight). A correction had to be made for the exclusion of new EU member states in Eastern Europe. Taking into account that mortality inequalities are about two times as large in these countries (i.e. a rate ratio of about 1.61) [16] and that these countries represent $17 \%$ of the population of EU-25, the rate ratio of 1.307 was adjusted to 1.36. The estimates were based on data that applied to the 1990s for Western European countries, and to about 2000 for Central and Eastern European countries. We assumed that the rate ratio of 1.36 had not substantially changed between these years and 2004 .

For ill-health, the rate ratio of 1.45 was derived from a re-analysis of data from national health surveys carried out in the early 2000's. Micro data from these surveys were acquired for the "Eurothine" study [17]. We selected data from 12 countries with identical survey questions on self-assessed health: Sweden, Norway, Denmark, England, Ireland, Belgium, France, Italy, Spain, Portugal, Hungary and the Czech Republic. For each country, we calculated the age-standardized prevalence of "less than good" selfassessed health for respondents with at least upper secondary education and for those with lower levels of education. For all countries together, the average prevalence rates were 43.7 and $28.9 \%$ for men with low and high educational levels, respectively. The corresponding values for women were 50.6 and $33.9 \%$. These rates implied a prevalence rate ratio of 1.51 for men, and 1.49 for women, the average being 1.50. These estimates did not include children and a substantial part of the elderly population, among whom inequalities in health are relatively small. We calculated that their inclusion would reduce estimates of the magnitude of health inequalities by about $10 \%$. We therefore adjusted the 1.50 estimate downwards to 1.45 .

Based on the absolute mortality rates, we calculated the absolute number of deaths for low and high educated persons in the European Union in 2004, and the total years of life lost due to all deaths 2004. The latter measure was obtained by multiplying the former with 16.06 years, which was shown in our analyses to be the average number of years of life lost per death in the European Union. 
Life table based measures express the burden of mortality and ill health in terms of the effect that current mortality and morbidity rates would have on the life of a hypothetical cohort of people exposed to these risks throughout their life. We calculated the life expectancy at birth according educational level, using period life tables for 2004. In addition, we calculated the "expectancy of life in poor health" per educational level, by multiplying the total life expectancy with the age-standardized prevalence of less-thangood health.

\section{ECHP analysis of the economic effects of ill health in lower educational groups}

In a second step, we determined the effects of ill-health in lower educational groups on earnings, assuming that salaries and wages reflect the value of a person's labour output, i.e. labour supply times labour productivity. We analyzed data of the European Community Household Panel (ECHP) conducted by Eurostat [18]. The ECHP is a survey based on a standardized questionnaire that involves annual interviewing of a representative panel of households and individuals of 16 years and older in each EU member state. We used data from the first to fifth wave, held in 1993 to 1997. Outcome measures (personal income, labour force participation etc) were taken from the fifth wave, while health variables were measured for waves 1, 3 and 5 respectively.

A key outcome parameter in our analysis was personal earnings, measured by personal income gained through work. We analyzed personal income in persons aged 16 to 64 years, excluding students, self employed workers, and unpaid family workers, and including those with zero income. Personal earnings were measured as gross monthly income, including salaries and wages, but not taking into account incomes from capital returns and social benefits. We supplemented the income analyses by studying the effect of health on labour market participation, number of hours worked, and hourly income. These three variables were considered as key components that together help to understand the effects of health on personal income. Labour force participation and utilization of unemployment benefits and disability benefits was analyzed in men and women in the age group 16 to 64 years, excluding students. We measured the rate of 
labour force participation, considering as economically inactive those who worked less than 8 hours per week (generally these are housewives, long-term unemployed, workdisabled and early retired).

Health was measured by self-assessed general health, with 5 levels: very poor, poor, fair, good, and very good. We used loglinear regression models with control for 5-year age group, sex and their interaction. In addition, we controlled for country and for marital status, which both may confound estimates of the effect of health on economic outcomes.

We conducted many alternative analyses in order to test the robustness of the findings. These included analyses with lagged effects of health as measured during previous waves on current income (which partly remove the effect of income on health, and more accurately measure the effect of health on income), analyses with other measures of health (i.e., presence of long-standing health problems with restrictions in daily activities, and having had to cut down daily activities due to health problems during the past 14 days), and analyses of spill-over effects of an individual's health on the income of their partner. While analyses with lagged effects of health showed that the cross-sectional associations between income and health are likely to overestimate the true effect of selfassessed health on personal income by $25-50 \%$, the other two analyses show that our estimates do not represent the full effect of health on income (results not shown) [14]. Because over- and underestimation appeared to be approximately equal in size, we present the results of the simplest (cross-sectional, unlagged) analysis.

Estimation of macro-economic effects of the burden of ill health and premature mortality in lower educational groups

In order to make a comprehensive estimate of the costs of the inequalities-related burden of ill health, we start from the notion that health is both a 'capital good' and a 'consumption good' [19]. As a 'capital good' health is an important component of 'human capital' (the value of human beings as means of production). Just like an adequate level of education, a good health status enables people to engage in formal and 
informal labour activities and to be productive. This value of health as a capital good can (partly) be captured by its effects on common economic measures such as labour participation, labour productivity and income.

The effects of health on personal income that were estimated made with the ECHP data (see above) were aggregated into an effect on Gross Domestic Product (GDP), taking into account that GDP consists of three components: (1) "compensation of employees" (gross earnings plus employers' social contributions); (2) "gross operating surplus and mixed income" (among which firm profits and earnings from self-employed persons); (3) "taxes less subsidies on production and imports". For the second component we assumed that $50 \%$ of firm profits can be ascribed to employees' productivity, and that the impact of a "levelling up" scenario on the gross earnings of self-employed persons will be $50 \%$ of the impact on employees' gross earnings.

The welfare loss of ill-health is not completely captured by the notion of health as a 'capital good', i.e. by its impact on income as defined in GDP. One arrives at a more complete estimate of this welfare loss when one considers that health is a 'consumption good' as well. As a 'consumption good', health directly contributes to an individual's 'utility' (economic language for 'happiness' or 'satisfaction'), because a good health status is enjoyable as such, and because a good health status enables individuals to enjoy work and leisure activities. The estimation of the value of health as a consumption good is, however, problematic as no market exists for health. In the literature different approaches for the valuation of health can be found, such as analyses of people's 'willingness to pay' in so-called contingent valuation studies [20] and analyses of past allocation decisions of health care authorities [21]. Unfortunately, although there is a consensus that health should be valued very highly, there is no consensus on a specific value of health.

Like others have done before us [3,22], we will loosely base our estimates on figures that were derived and proposed by the American economist Nordhaus [23]. Although work is underway to generate similar figures for Europe, this was not yet ready when this paper 
was written (2010). On the basis of a review of willingness-to-pay studies Nordhaus settled on a value of $\$ 3.0$ million (or appr. €2.3 million) per life saved, and a value of one current life-year of $\$ 100,000$ (or appr. $€ 77,000$ ). The first figure can be used to indicate the monetary value of avoidance of death at adult age (about 40 years), while the second figure can be used to indicate the monetary value of an additional year of life lived now. Nordhaus' estimate of $€ 2.3$ million per life saved is too high for our purposes, because it is based on estimates from labour market studies, which focussed on the economic importance of deaths among working-aged persons. The average loss of life years due to death at working age is considerably larger than the average loss of life years due to health inequalities in the general population. For Europe, we calculated a loss of about 16 years per death due to health inequalities, compared to about 40 years per death at working age. In order to account for this difference, we will assume that Nordhaus' estimate of $€ 2.3$ million should be reduced by $16 / 40^{\text {th }}$, i.e. to $€ 920,000$ per death avoided.

In addition to these costs in terms of health as a 'capital good' and as a 'consumption good' we calculated two other, more tangible cost categories, namely health care costs and costs of social security benefits. These cannot be added to the previous cost categories, but should be seen as societal expenditures which are incurred in order to cope with the damage to health as a capital and/or consumption good. Health care costs were estimated from the multivariately adjusted relationship between self-assessed general health and GP visits, specialist visits and hospitalization rates as observed in the ECHP dataset, and from OECD data on health care costs, assuming that the extra use of physicians and hospitals related to the excess ill health in lower educated groups can be generalized to health care as a whole. Costs of social security benefits were estimated from the multivariately adjusted relationship between self-assessed general health and receipt of disability benefits and unemployment benefits as observed in the ECHP dataset, and from OECD data on the total costs of these benefit schemes. 


\section{Results}

Table 1 presents our estimates of inequalities-related losses to health, in terms of mortality (deaths), morbidity (cases of fair/poor health), life expectancy (years of life lost), and expectancy of life with morbidity (number of years lived in fair/poor health). The number of deaths that can be attributed to health inequalities is estimated to be 707 thousand (the difference between the 4,6 million deaths which currently occur each year in the EU-25 as a whole, and the 3,9 million which would occur in an 'upward leveling' counterfactual scenario). The number of life-years lost due to these deaths (now and in the future) is about 11.3 million. Similarly, the number of prevalent cases of ill-health that can be attributed to health inequalities is estimated to be more than 33 million. As the reference period is one year (i.e. 2004), this number is equal to the current number of person-years-lived-with-health-problems which can be attributed to health inequalities. The lower part of the table presents estimates in terms of life table-derived measures. The estimated impact of health inequalities on average life expectancy at birth in the EU-25 for men and women together is 1.84 years, and that on life expectancy in fair/poor health is 5.14 years. This implies a reduction of the expectancy of life in good health by 6.98 years (the sum of 1.84 and 5.14 years).

In our analysis of the European Community Household Panel we observed large differences in the level of personal earnings according to the general health of people. Persons with "very good" or "good" health had about 4 times higher earnings than those with "poor" and "very poor" health. The relative impact of health on personal income was larger for lower educated persons. In absolute terms, health had a greater impact on personal income among the higher educated, because of the higher overall levels of personal income of higher educated compared to lower educated (figure 1). In our analysis, the main cause of lower earnings among those with poor health was their lower labour force participation. People with "very poor" health were about 2 times less likely to participate in the labour force than those with "very good" health. To a lesser extent the number of hours worked among economically active persons and hourly wages contributed to differences in income between persons with good and poor health. The effects of health on labour force participation, number of hours worked and hourly wages 
were generally larger (in relative terms) among persons with lower educational level (table 2).

Using the results of the 'levelling up' counterfactual scenario, which would reduce the number of persons in "very poor" or "poor" health states with more than 33 million (table 1), we estimate the health inequalities-related losses to salaries and wages in the European Union to be $2.8 \%$ (table 3 ). This translates into $€ 113$ billion, or a $1 \%$ loss in GDP for the EU as a whole. The total GDP impact is likely to be larger because part of the added value of employees' labor productivity is also included in firm profits, and because our estimate does not include the economic impact of health among the selfemployed. The impact on total GDP of health losses through these two additional effects is estimated to be around $0.7 \%$, or $€ 28$ billion for the EU as whole. The total costs of health inequalities in terms of health as a 'capital good' amount to €145 billion, or $1.35 \%$ of GDP.

The total costs of health inequalities in terms of health as a 'consumption good' are in the order of $€ 1000$ billion ( $€ 980$ billion, or $9.4 \%$ of GDP, in table 3). In a 'levelling up' counterfactual scenario, the yearly number of deaths due to health inequalities is 707,000 (table 1). If a life saved would be valued at $€ 920,000$, the total value of these losses would amount to $€ 650$ billion. We estimated the number of life-years lost by these individuals to be 11.4 million (table 1). If these life-years would be valued at $€ 77,000$ each, and one would take a standard discount rate of $1.5 \%$ per annum over an average of 16 years to take into account that these life-years will not be gained immediately, the total value of this loss in life would amount to $€ 778$ billion. Thus, the two alternative approaches to value the costs of annual deaths both yield estimates of about $€ 700$ billion, or $6.7 \%$ of current GDP. Inequalities-related losses to self-assessed health were estimated to be about 23 million cases of "fair" health and 10 million cases of "poor" health (table 1). These numbers imply 4.3 million years of life-in-good-health lost, which is $40 \%$ of the mortality effect of 11.4 million years (see above), which adds another $€ 280$ billion to the costs of health inequalities. 
The analysis of ECHP data confirmed that poor health was consistently related to GP visits, specialist visits and hospitalization rates. People with "very poor" health had more than 6 times more GP visits and more than 9 times more specialist visits than those with "very good" health, after adjustment for confounders. Virtually identical associations were observed within higher and lower educated groups. Our 'levelling up' scenario would decrease the number of GP visits and specialist visits by $16 \%$, and the number of nights in hospital by $22 \%$. We calculated the impact of health inequalities on health care costs to be €26 billion for physician services, and €59 billion for hospital services. According to OECD data, physician visits and hospitalizations represent almost half of total health care costs [22]. If the empirical results for physician visits and hospitalizations would apply to total health care, the total impact of health inequalities on health care costs would represent $€ 177$ billion, or around $20 \%$ of total health care costs in the EU-25 (table 3).

Our analysis of the ECHP panel data also confirmed that poorer health is strongly associated with receipt of disability benefits. People with "very poor" health on average receive about 20 times more disability benefits than those with "very good" health, after adjustment for confounders. Among lower educated groups, the effect of health on disability benefits is slightly smaller in relative terms. The association between poorer health and receipt of unemployment benefits was weaker, but in general, those with poor health received more unemployment benefits, after adjustment for confounders. On the basis of our 'upward levelling' counterfactual scenario we calculated that health inequalities account for $25 \%$ of the costs of disability benefits (representing $€ 55$ billion annually) and $3 \%$ of the costs of unemployment benefits (representing about $€ 5$ billion annually) in the EU as a whole (table 3). The total of $€ 60$ billion corresponds to $15 \%$ of the total costs of social security systems. 


\section{Discussion}

Our estimates suggest that the economic costs of socioeconomic inequalities in health may be substantial. While the estimates of inequalities-related losses to health as a 'capital good' (leading to less labour productivity) seem to be modest in relative terms (1.4\% of GDP), they are large in absolute terms (€141 billion). It is valuing health as a 'consumption good' which makes clear that the costs of socioeconomic inequalities in health are really huge: in the order of $€ 1000$ billion (or 9.4\% of GDP). The separately calculated impacts on costs of social security and health care systems and health care, which are incurred in order to cope with these losses to health as a 'capital good' and/or as a 'consumption good', support these conclusions. Inequalities-related losses to health account for $15 \%$ of the costs of social security systems, and for $20 \%$ of the costs of health care systems in the European Union as a whole. It is important to emphasize that all these estimates represent yearly values, and that as long as health inequalities persist, these losses will continue to accumulate over the years.

These estimates should be seen as a first attempt at coming to grips with these difficult issues. There are many uncertainties.

- First, although there are abundant data on the magnitude of socioeconomic inequalities in mortality and morbidity in the European Union, the comparability of data is limited, and some countries still lack relevant data [25]. As a result, our estimates of the magnitude of inequalities-related losses to health in terms of mortality and morbidity, life-years, and life expectancy with morbidity, as presented in table 1, have considerable margins of uncertainty. We think it likely that we have underestimated the inequalities-related losses to population health in the European Union, because of the measurement error inherent in the large-scale registries and surveys which we used for our calculations, and because of the fact that we have conservatively taken the upper half of the educational distribution as the reference category for our 'levelling up' scenario. Improved health monitoring systems are needed in the European Union to solve these problems.

- Second, our estimates of the monetary value of inequalities-related losses to health as a 'capital good' have a number of uncertainties. These uncertainties relate to the 
fact that we had to ignore losses generated through other mechanisms than the health effects on personal income. We could not take into account differences in savings between people in poor and in good health, and we had to ignore the value of informal labor. We also could not take into account the effect of ill-health on educational careers [26]. These uncertainties also relate to the validity and precision of the losses to personal income as calculated in the ECHP data. We assumed that the lower wages of lower educated people reflect the lower value of their contribution to the production of goods and services, but the validity of this assumption could be debated. We assumed that upward biases (e.g. due to a reverse effect of income on health) and downward biases (e.g. due to the fact that we largely ignored mental health problems and spillover effects of health on the earnings of partners) in the estimated effects of ill-health on personal income cancelled each other out, but this is clearly a very rough assumption. There is also no guarantee that what has been found in a single data set will be reproduced in other data sets, but we think that on the whole our estimates are likely to be conservative. There is an urgent need for systematic reviews and/or meta-analyses assessing the (causal) effect of ill-health on earnings in the European Union.

- Third, our estimates of the monetary value of inequalities-related losses to health as a 'consumption good' also have a number of uncertainties. There is no consensus among economists on the monetary value of health, and the accuracy of our estimates is therefore strongly dependent on the validity of Nordhaus' estimates for the value of a life saved and a current life-year lived [23]. In the literature, widely different estimates have been reported [27], but Nordhaus' estimates represent a conservative and well-documented choice and correspond reasonably well with some recent European estimates [28]. They were derived for the year 1990, and because more recent estimates for the United States are considerably higher [20], we may well have underestimated the monetary value of inequalities-related losses to health. On the other hand, the monetary value of health in 2004 might be lower in Europe than in the United States, if only because Gross Domestic Product in the EU-25 in 2004 was about 35\% lower - a difference which is also reflected in different recommended thresholds for determining cost-effectiveness of health 
technologies [29]. The $16 / 40^{\text {th }}$ fraction which we applied to Nordhaus' estimate of the value of a life saved was derived from an analysis of the actual life-years lost as a result of health inequalities in Europe, which is only $16 / 40^{\text {th }}$ of the life-years lost in Nordhaus'analysis. While one might argue that the value of life-years is not homogeneous across the life-course, we see no objective basis for such differentiation. Here again, there is an urgent need for more research in order to better support policy making in Europe, not only in the field of health inequalities, but in other health domains as well (e.g. health care policy, health research policy).

In order to illustrate the potential impact of these uncertainties on our findings we have performed a sensitivity analysis which is reported in table 4 . We selected five alternatives. A more radical 'upward levelling' scenario, in which the health of the whole population would be lifted up to that of the highest $20 \%$ instead of the highest $50 \%$, leads to substantially (i.e. about 60\%) higher estimates of the economic costs of health inequalities. On the other hand, if we use more conservative estimates of the effects of education, e.g. to take into account that part of the observed associations may not be causal or that we only had mortality data for a part of the EU-25, all four cost categories (capital good, consumption good, health care, social security) go down. The estimates of the impact on health as a capital good go down too, if we would assume a smaller than observed effect of health on personal income, or would assume no effect of health on firm profits or mixed incomes. The estimate of the impact on health as a consumption good go down if we lower Nordhaus' value of $€ 77,000$ for a life-year by $35 \%$, to take into account lower average GDP in the European Union as compared to the United States. The range of values shown in table 4 illustrates that uncertainties are indeed substantial, but do not shed doubt on our over-all finding that the economic costs of health inequalities are likely to be substantial.

Our results suggest that investing in programs to reduce health inequalities may have important economic benefits. During the past two decades, socioeconomic inequalities in health have increasingly been recognized as an important public health issue throughout Europe [30]. As a result, there has been a considerable research effort which has 
permitted the emphasis of academic research to gradually shift from description to explanation [31]. And as a consequence of that, entry-points for interventions and policies have been identified, providing the building-blocks with which policy-makers and practitioners have begun to design strategies to reduce socioeconomic inequalities in health. Although relatively little is known yet about the effectiveness of these strategies, it is possible to make some educated guesses about their potential impact on the economic implications of health inequalities in the European Union. For example, if it would be possible to implement a number of equity-oriented anti-tobacco policies which would reduce the prevalence of smoking in the lower socioeconomic groups by $33 \%$, while the prevalence of smoking in the higher socioeconomic groups would decline by $25 \%$ [32], our analyses suggest that a substantial impact would be generated. Not only would health inequalities be reduced considerably, but also some $7 \%$ of the economic costs of health inequalities through mortality and morbidity (including the costs of health care and social security benefits). Inequalities-related losses to health as a "consumption good' through mortality would be reduced by between about €75 billion for the EU-25 as a whole, and inequalities-related losses to health as a 'capital good' would be reduced by almost €9 billion per year [14].

The same could be true for policies targeting other 'downstream' determinants of health inequalities, like unfavourable working conditions or lack of access to good quality health care, and for policies targeting 'upstream' determinants of health inequalities, like barriers to higher education and income inequality. The effects of these policies are largely unknown, and the same applies to their costs. Some economists argue that income inequality is necessary for economic progress, so reducing health inequalities by income redistribution may entail high costs, even in terms of average population health [33]. This is still largely uncharted scientific territory, but in view of the sheer numbers highlighted by our analysis we think it likely that a good economic case for reducing health inequalities can be made - in addition to the more self-evident moral case which has so eloquently been made by the World Health Organization's Commission on Social Determinants [34]. 


\section{Acknowledgements}

The study was supported by the European Commission under contract number SANCO/2005/C4/Inequality/01. The analyses of ECHP data were performed by Heleen van Agt. 


\section{References}

1. Rosen G. A history of Public health (expanded edition). Baltimore: Johns Hopkins University Press, 1993.

2. Commission on Macroeconomics and Health, Working Group 5: Improving Health Outcomes of the Poor, 2001 (documents available at: www.cmhealth.org/docs)

3. Suhrcke M, McKee M, Sauto Arce R, et al. The contribution of health to the economy in the European Union. Brussels: European Commission, 2005.

4. Suhrcke M, Sauto Arce R, McKee M, et al. Economic costs of ill health in the European region. Copenhagen: WHO Europe, 2008. Also at: http://www.euro.who.int/_data/assets/pdf_file/0004/83443/E93695.pdf

5. Mackenbach JP. Health inequalities: Europe in profile. London: Department of Health, 2006.

6. Whitehead M. A typology of actions to tackle social inequalities in health. J Epidemiol Comm Health 2007;61:473-478.

7. Macintyre S, Chalmers I, Horton R, et al. Using evidence to inform health policy: Case study. BMJ 2001;27:222-225.

8. Adler NA, Boyce T, Chesney MA, et al. Socioeconomic status and health. The challenge of the gradient. Am J Psychol 1994;49:15-24.

9. Marmot M, Wilkinson R. Social determinants of health. Second edition. Oxford: Oxford University Press, 2006.

10. Whitehead M, Dahlgren G. Levelling up: a discussion paper on concepts and principles for tackling social inequalities in health. Copenhagen: WHO Europe, 2006. 
11. Ezzati M, Lopez A, Rodgers C, et al. Selected major risk factors and global and regional burden of disease. Lancet 2002;360:1347-1360.

12. Mackenbach JP, Kunst AE. Measuring the magnitude of socio-economic inequalities in health: an overview of available measures illustrated with two examples from Europe. Soc Sci Med 1997;44:757-771.

13. Lleras-Muney A. The Relationship Between Education and Adult Mortality in the United States. Rev Econ Stud 2005;72:189-221.

14. Mackenbach JP, Meerding WJ, Kunst AE. Economic implications of socioeconomic inequalities in health in the European Union. Brussels: European Commission, 2007. Also at website:

http://ec.europa.eu/health/ph_determinants/socio_economics/pub_socioeco_en.htm

15. Huisman M, Kunst AE, Andersen O, et al. Socio-economic inequalities in mortality among elderly people in 11 European populations. J Epidemiol Community Health 2004;58:468-475.

16. Mackenbach JP, Stirbu I, Roskam AJ, et al. Socioeconomic Inequalities in Health in 22 European Countries. N Engl J Med 2008;23:2468-2481.

17. Kunst AE, Stirbu I, Schaap MM, Roskam A, Mackenbach JP. Tackling health inequalities in Europe: the Eurothine project. Final Report. Rotterdam: Department of Public Health, 2007. Also at website: www.eurothine.org

18.

http://epp.eurostat.ec.europa.eu/portal/page?_pageid=1913,47567825,1913_47568298\&_ dad=portal\&_schema=PORTAL 
19. Grossman M. On the concept of health and the demand for health. $J$ Political Econ 1972;80:223-255.

20. Hirth RA, Chernew ME, Miller E, et al. Willingness to pay for a quality-adjusted life year: in search of a standard. Med Decis Making 2000;20:332-342.

21. Bootman JL, Townsend RJ, McGhan WF, eds. Principles of pharmacoeconomics. Cincinnati, OH: Harvey Whitney Books, 1991.

22. Luce BR, Mauskopf J. Sloan FA, et al. The return on investment in health care: from 1980 to 2000. Value Health 2006;9:146-156.

23. Nordhaus $W$. The health of nations: the contribution of improved health to living Standards. NBER Working Paper Series 8818. Cambridge, MA: National Bureau of Economic Research, 2002.

24. OECD Health Data 2006. Paris: OECD, 2006. Also at website: www.oecd.org

25. Kunst AE, Bos V, Mackenbach JP. Monitoring of socioeconomic inequalities in health in the European Union: guidelines and illustrations. Rotterdam: Erasmus MC, 2001. Also at website: www.erasmusmc.nl/mgz

26. Groot W, Maassen van den Brink H. Investing and earning. Costs and benefits of educational investments (in Dutch). Amsterdam: Stichting Beleids Onderzoek, 2003.

27. Olsen JA, Smith RD. Theory versus practice: a review of 'willingness-to-pay' in health and health care. Health Econ 2001;10:39-52.

28. Bickel P, Friedrich R. Externalities of energy. Methodology 2005 update. Brussels: European Commission, 2005. Also on website: www.externe.info 
29. http://www.who.int/choice/costs/CER_levels/en/index.html

30. Mackenbach JP, Bakker MJ and the European Network on Interventions and Policies to Reduce Inequalities in Health. Tackling socioeconomic inequalities in health: an analysis of recent European experiences. Lancet 2003;362:1409-1414.

31. Siegrist J, Marmot M. Social inequalities in health. New evidence and policy implications. Oxford (etc.): Oxford University Press, 2006.

32. Giskes K, Kunst AE, Benach J,et al. Applying an equity lens to tobacco-control policies and their uptake in six Western-European countries. J Public Health Policy 2007;28:261-80.

33. Deininger K, Squire L. Economic growth and income inequality: re-examining the links. Finance and Development 1997;34:38-41.

34. WHO Commission on Social Determinants. Closing the gap in a generation: Health equity through action on the social determinants of health. Geneva: World Health Organization, 2008. Website:

http://www.who.int/social_determinants/thecommission/finalreport/en/index.html 
"The Corresponding Author has the right to grant on behalf of all authors and does grant on behalf of all authors, an exclusive licence (or non exclusive for government employees) on a worldwide basis to the BMJ Publishing Group Ltd to permit this article (if accepted) to be published in JECH and any other BMJPGL products and sublicences such use and exploit all subsidiary rights, as set out in our licence (http://jech.bmj.com/site/about/licence.pdf)." 
Table 1. The population health impact of educational differences in mortality and morbidity in the EU-25 in 2004

$\left.\begin{array}{|lrrr|}\hline & \begin{array}{r}\text { Total EU-25 } \\ \text { population: } \\ \text { observed rates } \\ \text { and numbers }\end{array} & \begin{array}{r}\text { Total EU-25: } \\ \text { estimates } \\ \text { assuming rates } \\ \text { of higher } \\ \text { educated } \\ (1)\end{array} & \begin{array}{r}\text { Impact of } \\ \text { health } \\ \text { inequalities }\end{array} \\ \hline & & & (2)\end{array}\right)$

Notes to table 1:

[a] Source of observed mortality rate: Eurostat website. Mortality rates for the higher educated were derived from the observed mortality rate in the whole population, and a mortality rate ratio of 1.36 comparing lower educated and higher educated.

[b] Absolute numbers were obtained by multiplying rates or years by the total population size of EU25 in $2004(=458,973,000)$.

[c] Source of observed morbidity rate: Eurostat website. Prevalence rates for the higher educated were derived from the observed morbidity rate in the whole population, and the prevalence rate ratio of 1.45 comparing lower educated to higher educated.

[d] Source of observed life expectancy: Eurostat website. We interpolated estimates available for 2000 and 2005. Life expectancy for the higher educated was derived from the same data as described in note [a].

[e] Estimated on the basis of life expectancy and the prevalence of "less than good" health.

[f] The total years of life lost were estimated by multiplying the total number of deaths due to inequalities $(707,000)$ by an estimate of the average number of years of life lost per death $(16.06$ years). 
Note to figure 1:

Source: Analysis of the fifth wave of the European Community Household Panel, covering persons aged 16-64 in 11 countries in Western Europe, excluding students, self-employed workers, and unpaid family workers, and including those with zero income. Personal earnings were measured as gross monthly income, including salaries and wages, but not taking into account incomes from capital returns and social benefits. Results are based on a loglinear regression analysis controlling for age, gender, age*gender, cohabitational status and country. 
Table 2.

Educational differences in the effect of health status on personal income and its different components (all 16-64 years, excl. students, self-employed, unpaid work; 11 countries)

\begin{tabular}{|c|c|c|c|c|c|c|c|c|c|}
\hline & $\begin{array}{l}\text { Personal income } \\
\text { (gross, per } \\
\text { month) }\end{array}$ & & $\begin{array}{l}\text { Labour } \\
\text { force participation } \\
\text { (\% of population } \\
16-64 \text { yrs) }\end{array}$ & & $\begin{array}{l}\text { Number of } \\
\text { hours worked / } \\
\text { week }\end{array}$ & & Hourly & income & \\
\hline \multicolumn{10}{|l|}{$\begin{array}{l}\text { Summary measure of } \\
\text { effect, with } 95 \% \text { CI (a) }\end{array}$} \\
\hline - Low educated & $1.280 \quad(1.250$ & $1.300)$ & $1.046 \quad(1.041$ & 1.051) & $(1.012$ & $1.025)$ & 1.041 & $(1.031$ & 1.052) \\
\hline - Mid educated & $1.140 \quad(1.120$ & 1.160) & $1.030 \quad(1.024$ & 1.037) & $1.007 \quad(1.000$ & 1.013) & 1.025 & $(1.014$ & 1.037) \\
\hline - High educated & $1.140 \quad(1.120$ & $1.170)$ & $1.023 \quad(1.014$ & $1.031)$ & $1.009 \quad(1.001$ & $1.018)$ & 1.030 & $(1.014$ & 1.046) \\
\hline $\begin{array}{l}\text { Test (p-value) of } \\
\text { interaction (b) }\end{array}$ & $<0.0001$ & & $<.0001$ & & 0.0011 & & $<0.0001$ & & \\
\hline
\end{tabular}

(a) To be interpreted as the relative increase in the economic outcome per one unit increase in general health. Estimated with loglinear regression in which the dependent variable is health status measured at interval scale from 1 (for 'very bad') to 5 (for 'very good'). With control for age* gender, cohabitational status and country.

(b) Interaction between education (as 3-level nominal variable) and health (measured as the interval variable). Estimated with a loglinear regression model with control for age*gender, cohabitation status and country. 
Table 3. Estimates of the welfare impact of socioeconomic inequalities in health, EU-25 member states, 2004

\begin{tabular}{|c|c|c|c|c|c|}
\hline & \multicolumn{2}{|c|}{ Total value $[\mathrm{a}]$} & \multicolumn{3}{|c|}{ Impact of health inequalities [b] } \\
\hline & $\begin{array}{r}\text { In billion } \\
\text { euro }\end{array}$ & $\begin{array}{r}\text { As } \% \text { of } \\
\text { GDP }\end{array}$ & $\begin{array}{r}\text { As } \\
\text { oportion } \\
(\%) \\
\text { of each } \\
\text { item }\end{array}$ & $\begin{array}{r}\text { In billion } \\
\text { euro }\end{array}$ & $\begin{array}{r}\text { As } \% \text { of } \\
\text { GDP }\end{array}$ \\
\hline GDP of EU-25, 2004 & 10,451 & $100.0 \%$ & & & \\
\hline $\begin{array}{l}\text { Health as a capital good: } \\
\text { GDP income components }[c]\end{array}$ & & & & & \\
\hline - wages and salaries & 4,071 & $39.0 \%$ & 2.8 & 113 & $1.08 \%$ \\
\hline - firm profits; mixed income; etc & 4,021 & $38.5 \%$ & 0.7 & 28 & $0.27 \%$ \\
\hline - total income & 8,092 & $77.4 \%$ & 1.7 & 141 & $1.35 \%$ \\
\hline Health as a consumption good [d] & & & & & \\
\hline - mortality & n.a. & n.a. & n.a. & 700 & $6.7 \%$ \\
\hline - morbidity & n.a. & n.a. & n.a. & 280 & $2.7 \%$ \\
\hline - total health & n.a. & n.a. & n.a. & 980 & $9.4 \%$ \\
\hline Health care costs & & & & & \\
\hline - physician services & 157 & $1.5 \%$ & 16.4 & 26 & $0.25 \%$ \\
\hline - hospital services & 267 & $2.6 \%$ & 22.1 & 59 & $0.56 \%$ \\
\hline - total health services & 888 & $8.5 \%$ & 20.0 & 177 & $1.70 \%$ \\
\hline Social security benefits & & & & & \\
\hline - unemployment benefits & 178 & $1.7 \%$ & 2.7 & 5 & $0.05 \%$ \\
\hline - disability benefits & 222 & $2.1 \%$ & 24.7 & 55 & $0.53 \%$ \\
\hline - total benefits & 401 & $3.8 \%$ & 14.7 & 60 & $0.57 \%$ \\
\hline
\end{tabular}

[a] Source: Eurostat website or OECD website (health care costs).

[b] The impact of health inequalities was estimated on the basis of the estimates of inequalities-related losses to health as presented in table 1 . The $\%$ estimates in column 3 were multiplied with column 1 to obtain an estimate of the absolute amounts in column 4.

[c] In 2004, the average gross monthly income from wages and salary earnings in EU-25 was estimated to be €726 per person. Under the "levelling up" scenario, this average increases by 2.77 percent, to €746 per person. When only the impact of the "levelling up" scenario on gross earnings of employees is counted, the impact on total GDP will be $39 \%$ times $2.77 \%$, or $1.1 \%$ of GDP. Through firm profits and income of self-employed persons, a "levelling up" scenario will increase the second GDP component by (gross operating surplus and mixed income, accounting for $38 \%$ of GDP) by $0.7 \%$, which translates into $0.3 \%$ of GDP.

[d] See main text. 
Table 4. Results of sensitivity analyses.

\begin{tabular}{|c|c|c|c|c|c|c|}
\hline & \multicolumn{6}{|c|}{ Impact of health inequalities (in billion euro) } \\
\hline & $\begin{array}{l}\text { Standard estimates } \\
\text { (as in table 3) }\end{array}$ & $\begin{array}{l}\text { Alternative 1: } \\
\text { the health of people } \\
\text { is "leveled up" to } \\
\text { the highest } 20 \% \text { of } \\
\text { the population, } \\
\text { instead of the } \\
\text { highest } 50 \% \\
\end{array}$ & $\begin{array}{l}\text { Alternative 2: } \\
\text { educational } \\
\text { differences in } \\
\text { health are } 30 \% \\
\text { smaller than } \\
\text { empirically } \\
\text { estimated } \\
\end{array}$ & $\begin{array}{l}\text { Alternative 3: } \\
\text { the effect of } \\
\text { health on income } \\
\text { is } 30 \% \text { smaller } \\
\text { than estimated } \\
\text { using ECHP data }\end{array}$ & $\begin{array}{l}\text { Alternative 4: } \\
\text { health has no } \\
\text { effect on firm } \\
\text { profits and mixed } \\
\text { incomes }\end{array}$ & $\begin{array}{l}\text { Alternative 5: } \\
\text { one life-year is } \\
\text { worth } 35 \% \text { less } \\
\text { than the US based } \\
\text { estimate of } \\
77,000 \text { euro }\end{array}$ \\
\hline Health as a capital good & 141 & 226 & 108 & 99 & 113 & n.a. \\
\hline Health as a consumption good & 980 & 1568 & 754 & n.a. & n.a. & 637 \\
\hline Health care costs & 177 & 283 & 136 & n.a. & n.a. & n.a. \\
\hline Social security benefits & 60 & 96 & 46 & n.a. & n.a. & n.a. \\
\hline
\end{tabular}

Same notes apply as to table 3. For explanation of alternative scenarios, see main text. 


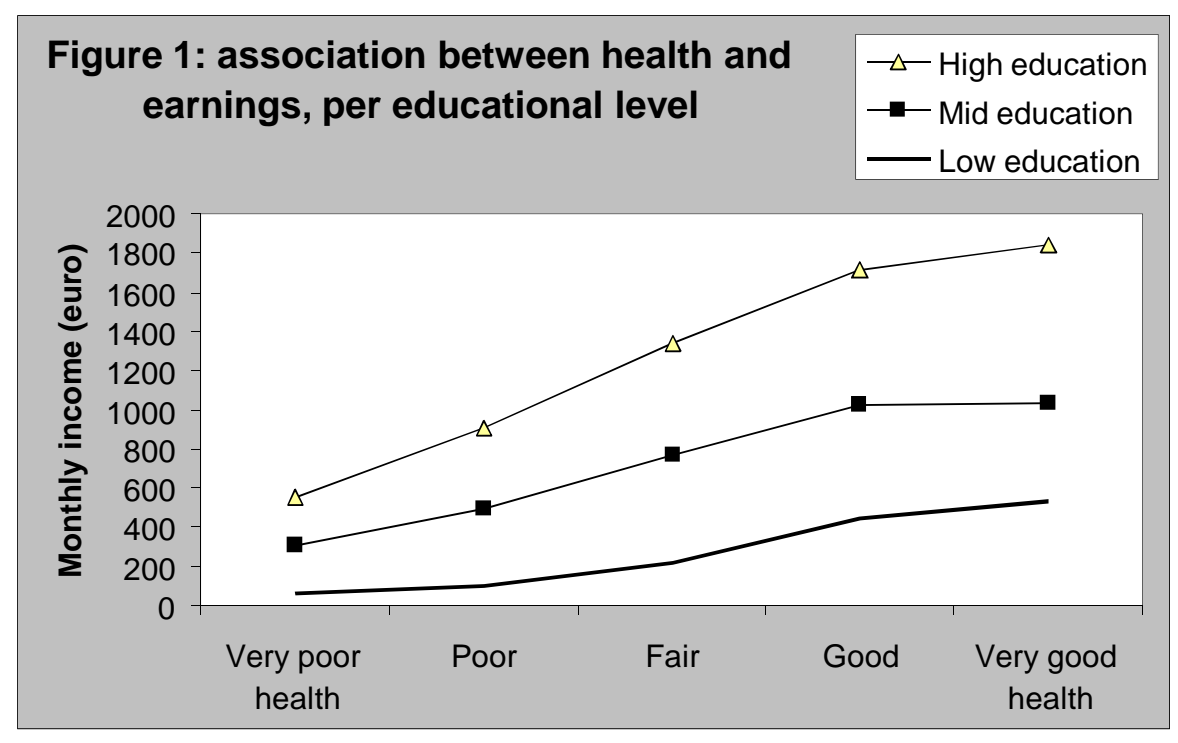

